\title{
Operational Efficiency of School-Based vs. Community-Based Summer Food Service Programs
}

\author{
Jeremy E. Whaley ${ }^{1, *}$, Kiwon Lee ${ }^{2}$, Rochelle A. Butler ${ }^{3}$ \\ ${ }^{1}$ Department of Retail, Hospitality, and Tourism Management, The University of Tennessee, Knoxville, United States of America \\ ${ }^{2}$ Hospitality Management, Kent State University, Kent, United States of America \\ ${ }^{3}$ OIT Research Computing Support ITR III, The University of Tennessee, Knoxville, United States of America \\ *Corresponding author: jwhale15@utk.edu
}

Received January 24, 2019; Revised March 03, 2019; Accepted March 21, 2019

\begin{abstract}
The purpose of this study was to assess costs and sales (i.e., operational efficiency) associated with two summer food service programs (SFSPs): a local school district operated one program, and a community organization, with the assistance of a state-administered food bank, operated the other program. The researchers proposed possible solutions to operational inefficiency based on a case study approach to study the costs (i.e., food, labor, and administrative expenses) and sales of these two programs. They utilized the participants' observations and source documents in phase one followed by gathering focus groups, composed of key stakeholders, in phase two. The results showed four major themes concerned each site's respective SFSP: cost management, program barriers, program management, and atmospherics. To address the overarching concerns with the community-based program operating metrics, the researchers asked if the utilization of non-violent, work-release inmates and food trucks reduced costs or increased sales, or both. child nutrition professionals can utilize the results of this study to increase operational efficiency in their SFSPs. The implications support the need for additional funding for each program and for training and development in the areas of food system operational management for the community-based program and creative marketing to reach more children in the summer months.
\end{abstract}

Keywords: food cost, labor cost, administrative cost, summer food service program (SFSP), qualitative study

Cite This Article: Jeremy E. Whaley, Kiwon Lee, and Rochelle A. Butler, "Operational Efficiency of School-Based vs. Community-Based Summer Food Service Programs." Journal of Food and Nutrition Research, vol. 7, no. 3 (2019): 237-243. doi: 10.12691/jfnr-7-3-9.

\section{Introduction}

Institutionalized food service operations face a multitude of challenges from the need to provide healthier food options to an ever-increasing need to control costs and maximize profits. [1] First are the food costs, followed by the labor costs, which continue to rise as preparing and serving healthier foods may require unique cooking methods. [1] The third cost includes other operating costs such as utilities and administrative costs. These three costs-food, labor, and other operating expenses-are the prime costs for food service operations.

The United States Department of Agriculture (USDA) Food and Nutrition Service (FNS) oversees multiple child nutrition programs. [2] During the academic school year, the School Breakfast Program (SBP) and the National School Lunch Programs (NSLP) provide meals to all children. However, when school is not in session, millions of low-income children lose their opportunities for receiving school meals and are at risk of hunger. [3]

In response, the Summer Food Service Program (SFSP) is designed to serve nutritious meals to children during the summer months when school is not in session. Various community-based organizations, including local government agencies, residential summer camps, faith-based, and other non-profit organizations operate summer food service programs. [2] SFSP sites have to receive approval to operate in areas where $50 \%$ or more of the students depend on free or reduced-price school lunches, and the local population is below $185 \%$ of the federal poverty line. [4] Other criteria for organizations that seek to participate in SFSP include being tax exempt and the ability to demonstrate the administrative and financial abilities of food service management. [2] Another criterion to operate an SFSP is for sites to have the ability to market these programs through public communications such as flyers. [3] Each potential feeding site must be state-inspected and seek state approval to operate a program. [3]

Depending on who the program serves (e.g., students participating in summer school or open to the public) and where to serve (e.g., open site or not), the SFSP, the School Breakfast Program (SBP), or the NSLP with the Seamless Summer Options (SSO) reimburses schools for offering summer meals. [5] Schools participating in the SSO should serve children in the community at large and operate open sites. The SSO, as an alternative to SFSP, allows schools to serve free summer meals. The SSO has the same criteria as meal service locations, meal costs for 
children, site eligibility, types of meals, the maximum number of meals, and commodities as those of the SFSP and variations in other aspects (times of operation, meal service time requirements, etc.). Whereas the SSO follows the same guidelines and nutritional requirements as the nine-month academic school year feeding schedule, the SFSP can choose its meals as long as they meet the traditional nutritional requirements. In July 2016, these summer meal programs served lunches to nearly three million children per day. [6]

Previous studies on supplemental nutrition programs have examined the contributions of meals served to reduce hunger. [7,8] Nord and Romig found that seasonal differences in food insecurity (usually higher in summer than spring) are smaller in states with more widespread participation in the supplement nutrition program and summertime school lunches. [8] These summer meals reduce the prevalence of food insecurity, especially in low-income households with school-aged children. [8] On the other hand, Miller found that geographical accessibility to summer meal sites was not related to food insecurity for low-income households. [4]

While the researchers reviewed articles related to SFSPs, their examination revealed that child meal programs, specifically these supplemental programs, are virtually unstudied regarding the daily approach to operations related to revenues and costs (i.e., operational efficiency). Researchers reported a critical need for policy updates and research of SFSPs given that eating habits and food trends change continuously and food insecurity remains a significant concern for many children. [9]

In order to address the concerns about food insecurity, Cotugna and Vickery evaluated the SFSP by observing food waste and interviewing children. [10] The authors found that traditional items (e.g., peanut butter and jelly sandwiches) received higher food rating evaluations than food items such as pita sandwiches. [10] The researchers also found that $18 \%$ of students claimed that lunch meals seemed inadequate. Although both state and federal governments attempted to increase the nutritional value of food and the quality of taste, many children remain obese [11].

As part of promoting healthier lifestyles, Evans et al. explored the implementation, test adherence, and the preliminary effectiveness of preventative measures against summer-time weight gain among low-income youth. [11] While there was modest involvement $(65.6 \%)$ by those who participated in the intervention procedures (e.g., physical activity and free lunch via USDA's SFSP), the authors' preliminary findings suggested a decrease in participants' body mass index (BMI) [11] Thus, SFSPs can serve many purposes, such as decreasing food insecurity in the summer months, and the programs may provide students with a way in which to be physically active and involved in the communities when school is not in session.

The SFSPs are federally funded, state-administered programs that provide reimbursements to programs that serve meals to children. [11] The USDA provides sponsors with administrative guidance, which includes information about the recordkeeping of meal counts and operating, labor, and administrative costs. [12] However, non-traditional foodservice providers interested in starting up or maintaining an SFSP may experience difficulties in adhering to USDA guidelines. On the other hand, experienced child nutrition professionals responsible for regular feeding during the academic school year would most likely not have any difficulty in following the USDA guidelines.

Therefore, the evaluation of the revenues and the costs of these two programs may shed light for new SFSP administrators as well as those who are traditional program managers. Exploring both the operational challenges and the operational benefits will assist program administrators in the effective operation and maintenance of these vitally essential summertime programs. Exploring both operational benefits and challenges these programs experience during the summertime months is crucial to maximizing the potential effects of these programs that are responsible for feeding millions of children each year. [13]

Of additional importance, a significant variety of USDA food assistance programs, for example, the Women, Infants, and Children Program and the Supplemental Nutrition Assistance Program, are actively evaluated by state governments for their success. [14,15] An assessment of the revenues and costs associated with these two types of SFSPs will give researchers and policymakers directions for future actions to improve operational success.

Against this background, this study assessed and compared the revenue and costs of two SFSPs based on three operating metrics provided by the USDA framework (food, labor, and administrative costs). The operating metrics included the number of daily participants; food, labor, and administrative cost; and reimbursable meals. [12]

\section{Methodology}

Upon Institutional Review Board (IRB) approval, the research began in the summer of 2013. For this study, food, labor, and administrative were obtained from each respective feeding site to analyze daily operations. Also, as a follow-up to the quantitative portion of the study, the researchers conducted focus group interviews.

\subsection{Study Sites}

The researchers selected these sites based on a convenient sample and initially emailed the site managers. The researchers chose one school-based program (SBP) and one community-based program (CBP) for comparison. The locations of both programs were the same state in the southeastern portion of the United States. The schoolbased program reported that it served, on average, more than 5,000 meals during the summertime and began this summer meal service from mid-May until the end of July each year. The SBP served meals in the summertime from 1993 until the present day. A private, non-profit organization and a state-funded food network operated the CBP from June 1 until June 30 each year. The CBP reported that the organization projected to serve more than 1,500 meals during the summertime. It is important to note that the CBP was in its first year of summer-time operations at the time of this research. 


\subsection{Data Collection and Analysis}

The researchers conducted the study in two phases. In the first, they asked to visit the site(s), observe daily operations, speak with the program manager(s), and obtain key operating metrics related to the SFSP. In the second, they conducted focus group interviews to understand each program's approach to revenue production and the management of food, labor, and administrative costs.

In phase one, the researchers created an instrument to collect each of the operation's four primary metrics from sourced documents (e.g., invoices) provided by the program managers. The SBP started summer feeding a few weeks before the CPB. Thus, the researchers chose to compare one month of primary metrics. The program managers collected data in June from each operation because of the comparable number of days needed to produce comparative results for the daily operations.

In phase two, the researchers conducted focus group interviews with SFSP professionals and key employees. The focus group interviews took place the following summer of 2014 at both locations. The researchers used a structured interview guide to provide an organization for the focus group interviews. The researchers provided informed consent, and the participants understood that the focus groups were audio recorded. Recording the focus group interviews was necessary because the researchers could later review and slow the recordings to ensure reflexivity during the process of transcription. [16,17,18] The researchers followed the methods for the qualitative inquiry as prescribed by Kleiber [19].

The researchers developed the questions for the focus group interviews from the data collected in phase one of the study. They recruited the study participants via the program director of each program (e.g., some members of the management team and some members from the operations team to provide a wider range of experiences). While the researchers made attempts to gather as many as 10 participants for each session, this was not feasible due to the limited amount of key personnel in each program. Two faculty members in a local university's Nutrition Department reviewed the focus group questions for clarity and reliability. After each focus group, the researchers reviewed the discussions to ensure that the audio that the researcher recorded matched the theme and contents of the participants' expressions $[17,18]$.
For the school-based program, the researchers recruited eight individuals; however, due to organizational conflicts on the day of the focus group, only two individuals attended the session, and both were SFSP administrators. For CBP, five stakeholders participated in the focus group interview. Participants in each of the focus groups were provided with retail gift cards in \$25 increments for one hour of participation.

Qualitative analysis of the interviews used an iterative and repetitive coding process with the help of NVivo11, a computer-aided qualitative data analysis software program. The researchers conducted both manual and thematic analysis of the data. NVivo 11 software helped the researchers organize the interview data and code the text. First, the researchers analyzed the coded transcripts for reliability by using thematic analysis, and the coders obtained an intercoder agreement of $>95 \%$ for all indicators. [20,21]

Second, the researchers coded the transcripts by the content of each question asked during the focus group and by emergent themes. Consequently, codes represented concepts within the interview questions and concepts that emerged during the discussions.

\section{Results}

\subsection{Operational Metrics}

Table 1 displays the results of the operational metrics that the researchers gathered in phase one. Income from both of the programs came from the sale of meals at each site and other food-related items that were not deemed reimbursable from the USDA, which, at the specific time the research, were things such as candy bars and sodas. It is important to note that this research took place before the Smart Snacks Initiative.

The SPB obtained total sales of $\$ 26,789.04$, whereas the CPB reported sales of $\$ 4,837.20$. Also, the schoolbased program served a total of 7,916 meals. On the other hand, the community-based program sold a total of 1,668 meals. Regarding participation rates, the CPB served approximately 70 meals per day, and the SPB served 396 meals per day, and all of the participating children were served a free lunch as the area qualified for more than $50 \%$ of the local population being eligible to eat free.

Table 1. Metrics of Operational Efficiency

\begin{tabular}{|c|c|c|c|c|}
\hline Operational Metric & SPB-June 2013 & Percent-age & CPB-June 2013 & Percentage \\
\hline Total Meals Served & 7,916 & & 1,668 & \\
\hline Average Daily Meals Served & 396 & & 70 & \\
\hline *Total Sales & $\$ 26,789.04$ & $100 \%$ & $\$ 4,837.20$ & $100 \%$ \\
\hline Average Daily Sales & $\$ 1,030.35$ & & $\$ 201.55$ & \\
\hline Food Cost & $\$ 7,461.30$ & $27.86 \%$ & $\$ 4,793.15$ & $99 \%$ \\
\hline Labor Cost & $\$ 11,529.67$ & $43.04 \%$ & $\$ 3,249.00$ & Not Covered \\
\hline Administrative Costs & $\$ 3,023.34$ & $11.29 \%$ & $\$ 1,167.48$ & Not Covered \\
\hline Total Costs & $\$ 22,014.31$ & $82.18 \%$ & $\$ 9,209.63$ & \\
\hline Total Reimbursements & $\$ 25,826.54$ & $96.40 \%$ & $\$ 4,003.40$ & $82.76 \%$ \\
\hline
\end{tabular}

* includes meals and snacks. 
The SPB yielded a food-cost percentage of approximately $28 \%$. For the CPB, this percentage was 99\%. The SBP spent almost half of its total sales on labor costs $(43 \%$, $\$ 11,529.67)$ and approximately $11 \%$ of sales on administrative costs $(\$ 3,023.34)$. The CPB spent most of its sales on food, so money for skilled labor to $\operatorname{cook}(\$ 3,249.00)$ and administration $(\$ 1,167.48)$ could not be covered by the daily operations via reimbursement for the meal counts. As such, a state-run food network funded labor costs and administrative costs via a grant with specific requests as to the application of the funds within the operation (i.e., the grant could not cover food-related expenses). Thus, outside funding was sought to cover these related costs as the CBP could not pay all of its critical operating expenses.

The SBP received total reimbursements from the USDA of $\$ 25,826.54$ (slightly lower than the program's total sales) and produced a profit of close to $\$ 4,000$. The community-based SFSP received the total reimbursement of this profit, which covered only its food-related costs. From the results of the operating metrics, the results are evident in that the SBP produced a profit without assistance from outside funding sources. On the other hand, the community-based program produced an operating loss. Thus, the researchers employed focus groups to shed light on the operational intricacies of the daily activities.

\subsection{Focus Group Interviews}

Although the focus group questions remained the same between the two groups, the content and outcome of the focus groups were uniquely different. Four common themes emerged from the groups: (1) cost management, (2) program barriers, (3) program management, and (4) environment/atmospherics. However, the directions of each theme differed between these two programs.

\subsubsection{Cost Management}

A word cloud (Figure 1) depicting the 15 most frequently used words in one program indicated that the participants discussed money and budgets. From a review of the operating metrics, the cost of food was a common concern for both programs.
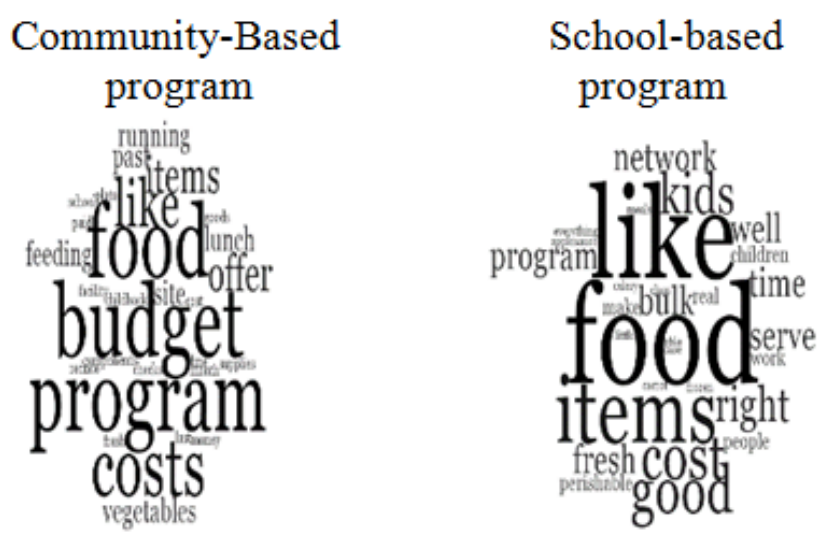

Figure 1. Word Clouds for Operational Efficiency

From the SPB, one focus group participant expressed concern over marketing the program, effectively, to increase student participation and to lower food costs.

"We have been lucky in that [participant 2] is very resourceful. We use the same banners from month to month and year to year. A PR firm charges a monthly rate of around \$250. Getting the word out helps with our participation rate; this helps lower our overall food cost.”

On the other hand, the community-based program described methods for reducing food costs with unique food preparation.

"One thing that we did do, when we were getting celery was to serve celery sticks or carrot sticks. The kids weren't eating the fresh vegetables as much. As we started serving the vegetable soups to where we could start putting the carrots and celery and stuff in it."

From phase one, the results showed that the CBP received existential funding to cover labor and administrative costs. In the follow-up interview, the participants highlighted concerns about the local workforce (e.g., volunteers) and labor cost concerns. From the CBP, one focus group participant expressed concern over the amount of labor needed to run the program,

"The more hands you got available, the easier things will flow 'cause sometimes we don't have enough in here to maintain what happens out there."

The community-based program focused on what kids liked for the cost and how the administrators could stretch the budget to please the children. One focus group participant stated,

“The kids were kind of hesitant; they wouldn't eat the applesauce so, what we did was try to make a smoothie using the applesauce and the strawberry milk and adding a little ice to it.”

\subsubsection{Program Barriers}

These surfaced as a theme in each focus group related to costs and operational efficiency. Barriers included program marketing, safety issues, training and development, and transportation to the feeding site. Program profitability and resistance to change were barriers discussed in the school-based program. However, transportation was the most significant consideration in the community-based program, along with the creative preparation of foods.

For example, statements like the one below reflected program barriers in the school-based program:

"A lot of school districts do not have a cooperative agreement like we do with the Boy's and Girl's Club. Typically, the Boy's and Girl's Club hosts its own summer feeding programs. Ours locally does not. So, if we were to rely on just the programs in our own schools, we would be at the mercy of those programs. So if there were no kids, it would be very difficult to expect people off the street to walk in and keep our business selfsustaining. Limiting factors would probably be the school district's support from other school districts."

On the other hand, program barriers working against operational efficiency in the CBP were reflected in the following statement concerning transportation to the feeding site:

"It's certain apartment spaces that are low-low-wealth neighborhoods and, if we had transportation to be at that site to pick up and drop off, we could feed a whole lot of children.”

\subsubsection{Program Management}

The focus group discussions validated the differences in program management. Each site manager approached 
his/her operation differently. For instance, the following statement reflected a differing managerial approach for the school-based SFSP program regarding operational efficiency:

"Because it was just...there's a tense environment. What we have done is make it more retail friendly, and we've offered some ala carte options in the summer. These aren't things that are on Styrofoam and institutionalized. We want to create more of a café environment."

Conversely, the following statement represented the differing, yet creative, managerial style in the CBP in that the director effectively included the kids in marketing the program: "I went around the first day when we first started the meals on the bus and I had some of the kids ride with me, handing out the flyers and going in the homes where they knew had children.”

\subsubsection{Environment/Atmospherics}

Uniquely, both focus groups stated that the environment for the children plays a significant role in the willingness of students to participate in the programs. The following statement represents a quote related to atmospherics from the school-based program:

"We like to keep it modern; we like to keep it free of constraints. We have just recently renovated our high school cafeteria. They enjoy freedom, and by that means they are in there more and guess what they are going to do while they are in there more? They are going to spend money. That participation goes up, and now we have more money to hire more people, bring in better products that have a higher cost, but ultimately sell quicker.”

However, the atmospherics of the community-based program took on a different meaning. It was apparent that the cost of improving atmospherics would be out of reach for the program. In the community-based program, substantial barriers were present. This program shared outside activities that could liven up the program for their students by engaging them in an activity that they would enjoy. A statement from the community-based program suggests the following:
"She starts planning this after we do our Martin Luther King parade because we just go all out doing this parade. Sometimes we have enough funds that someone has been generous enough, and we have gas to use our bus, and we go out to a local community.”

\section{Discussion}

The research was conducted to provide insight into the operational efficiency of two SFSPs. Through the analysis of operational metrics and focus group interviews, the researchers concluded that the two types of summer nutrition programs display different operational efficiencies. For example, the school-based SFSP displayed a more contemporary approach to operational efficiency by transforming its traditional utilitarian atmosphere into more of a restaurant atmosphere. Conversely, the CBP operated at a significant disadvantage when compared to the SBP; however, that did not stop the drive to feed the local children regardless of the cost of the extra time and effort that it took (e.g., staffing issues or the administrator working above and beyond work hours for compensation).

Furthermore, the researchers found that the two programs differed in many ways, however uniquely, and each site manager displayed a keen operational awareness of what it took to market each of the programs (e.g., posting flyers/communication, working with local organizations such as churches and summer camps). Figure 2 displays each program's approach to marketing in each community. The site manager for the communitybased program suggested the "food needs to be clean and presentable and that she worked closely with the local churches to get the word about the community-based SFSP." The site manager for the school-based program suggested that he "utilized the school district website and social media outlets and placed banners out in front of the school and dropped off flyers and materials at the local post offices."

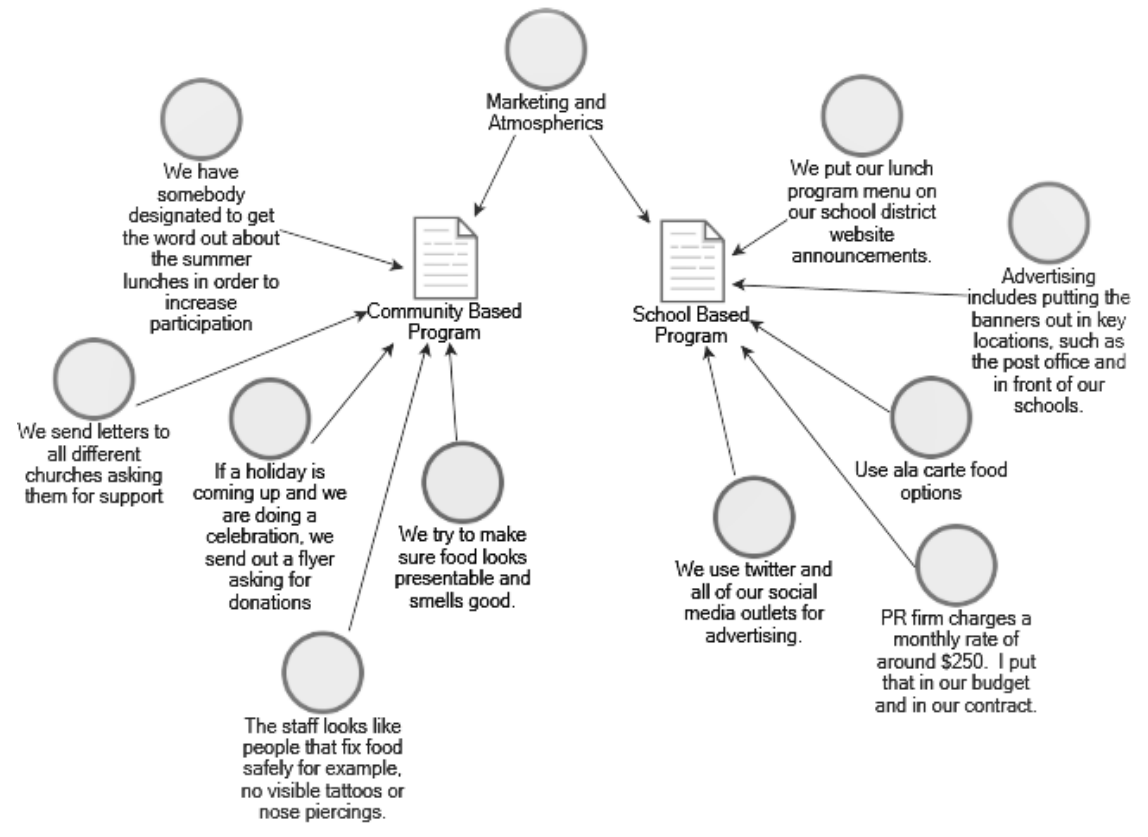

Figure 2. Approaches to marketing between the two SFSPs 


\section{Efficiency Solutions}

The researchers discussed possible solutions to improve operational efficiency within the focus groups in that there are two possible improvements: produce more sales or reduce costs. Given this, the researchers included using food trucks to increase sales. In order to cut costs related to labor, use non-violent offenders for food service-related work [22] and use the food truck to decrease food insecurity are feasible. [23]

\subsection{Use of Non-Violent Public Offenders}

The use of these offenders was queried in each respective focus group. Given that staffing required physical labor and managing the community-based program was also a significant concern, perhaps the use of these offenders could assist the site managers. The following statement reflects a thought on this possibility: "The only thing with that is we have to go through our license through the state and it depends on the person's offense"

Labor was not a concern of the school-based program. Thus, the researchers did not inquire about it during the focus group interview.

\subsection{Use of a Food Truck}

As an additional theme to increase the overall operational efficiency of each program, the use of a food truck to increase the participation rate, as this rate is essential to improving operations. Both groups discussed the pros and cons of utilizing a food truck for the SFSP.

The following statement came from a community-based program participant: "I think it would really significantly increase the participation in this city." As similar statement came from a participant in the school-based program: "If you could drive that truck through a neighborhood and distribute 100 meals in one day, and go to the next one over, and distribute another 100 meals, you know, that would be huge."

The school-based SFSP has access to many more students, and thus produces higher operating metrics and operational efficacy as it pays all of its costs associated with operating the SFSP. The community-based program is in great need of funding to sustain its operations and to make necessary improvements to the facilities in order to attract more students from the community. Still, the community-based program provides the same service to low-income families and students who would otherwise go hungry in the summer months. Even though the grant provided supplemental funds for these next two summers, the food network may not receive a grant in the future to sustain its operations.

It is important to note that the community-based program serves children whose parents are not likely to drive or have access to transportation. The scope of the community-based operation is small in comparison to the larger school district in the study. It needs significant external funding to continue to offer services to low-income students.

\section{Limitations}

Given that this research is more qualitative than quantitative, the researchers may have missed or misinterpreted some of the meanings of the statements within the focus group transcripts. Also, food service operations may measure operational efficiency in a variety of different ways. Some operations may focus on food and labor, whereas other may focus only on labor costs. Also, this study chose one venue for each summer food service program. It would be ideal to get a consensus among several organizations at each venue to avoid the confounding effects of the unique characteristics of each operation.

\section{Conclusion}

Food, labor, and administrative costs of SFSPs will continue to rise, and therefore SFSP managers and administrators will experience these increasing operational metrics. Operators who understand the critical areas of operational efficiency and can manage these key metrics will become increasingly important. While formal food service education can be most helpful in managing daily operations, the value of operational experience is, without a doubt, a valuable asset to these programs.

\section{References}

[1] Pitts, S., J., Schwartz, B., Graham, J., Warnock, A. L., Mojica, A., Marziale, E., and Harris, D, "Best practices for financial sustainability of healthy food service guidelines in hospital cafeterias,” Preventing Chronic Disease, 15 (58). 2018.

[2] United States Department of Agriculture, “Administration guide: summer food service program,” Retrieved July 24, 2018, from https://fns-prod.azureedge.net/sites/default/files/sfsp/ SFSP_Admin_Guide_Sept2016.pdf. 2017.

[3] United States Department of Agriculture, "How to participate in summer meals”, Retrieved January 31, 2019, from https://www.google.com/url?sa=t\&rct=j\&q=\&esrc=s\&source=we b\&cd=2\&ved=2ahUKEwjLl8qy9ZjgAhVL_IMKHU5KB10QFjA BegQIBhAG\&url=https\%3A\%2F\%2Ffnsprod.azureedge.net\%2Fsites\%2Fdefault\%2Ffiles $\% 2$ Fsfsp\%2FSFSP-Fact-Sheet.pdf\&usg=AOvVaw 2XBLBIRT7b18q50FQGeT4B. n.d.

[4] Miller, D.P, "Accessibility of summer meals and the food insecurity of low-income households with children”, Public Health Nutrition, 19 (11). 2079-2089. 2016.

[5] Duran, C, "Seamless summer option. Provides free, nutritious meals to New Mexico's children when school is out," Retrieved January 31, 2019, from

https://www.google.com/url?sa=t\&rct=j\&q=\&esrc=s\&source= web\&cd=2\&ved=2ahUKEwi-

n4uNgJngAhWlz4MKHWyVA6QQFjABegQICBAC\&url =https\%3A\%2F\%2Fwebnew.ped.state.nm.us\%2Fwpcontent\%2Fuploads\%2F2018\%2F01\%2FSeamless-Summer-2017Presentation.pptx\&usg=AOvVaw0YY-ZFIQGIGhbqGmO4wNq_, (n.d.).

[6] Food Research and Action Center, Hunger doesn't take a vacation: Summer nutrition status report. Retrieved May 18, 2018, from http://frac.org/wp-content/uploads/2017-summer-nutrition-report1.pdf. 2017.

[7] Bartfeld, J. and Dunifon, R, "State-level predictors of food insecurity among households with children," Journal of Policy Analysis and Management, 25 (4). 921-942. 2006. 
[8] Nord, M, and Romig, K, "Hunger in the summer: seasonal food insecurity and the national school lunch and summer food service programs," Journal of Children and Poverty, 12 (2). 141-158, 2006.

[9] Hopkins, L.C. and Gunther, C, "A historical review of changes in nutrition standards of USDA child meal programs relative to research findings on the nutritional adequacy of program meals and the diet and nutritional health of participants: Implications for future research and the Summer Food Service Program,” Nutrients, 7 (12). 10145-10167. 2015.

[10] Cotugna, N. and Vickery, C. E, "Children rate the summer food service program”, Family Economics and Nutrition Review, 16 (1). 3. 2004.

[11] Evans, E. W., Bond, D. S., Pierre, D. F., Howie, W. C., Wing, R. R. and Jelalian, E, "Promoting health and activity in the summer trial: implementation and outcomes of a pilot study," Preventive Medicine Reports, 10. 87-92. 2018.

[12] US Department of Agriculture, Food and Nutrition Service Program Information Report; (keydata) US summary, FY 2014-FY 2015. Retrieved July 24, 2018, from http://www.fns.usda.gov/sites/default/files/datastatistics/KeydataJanuary-2015.pdf. 2015.

[13] Feeding America, "Summer food service program; summer feeding program \& local food Banks,” Retrieved February 4, 2019, from

https://www.feedingamerica.org/our-work/hunger-reliefprograms/summer-food-service-program. 2018.

[14] Mabli, J., Ohls, J., Dragoset, L., Castner, L, and Santos, B, Measuring the effect of Supplemental Nutrition Assistance
Program (SNAP) participation on food security (No.69d901432c7a46779666a240a0974a5d). Mathematica Policy Research. 2013.

[15] Santos, B, "Measuring the effect of supplemental nutrition assistance program (SNAP) participation on food security" (Executive Summary), 1. 2014.

[16] Carlson, J. A, “Avoiding traps in member checking," The Qualitative Report, 15 (5). 1102-1113. 2010.

[17] Braun, V. and Clarke, V, Successful qualitative research: A practical guide for beginners, Sage, London, UK, 2013.

[18] Clarke, V., \& Braun, V, "Teaching thematic analysis: overcoming challenges and developing strategies for effective learning,” The Psychologist, 26 (2). 120-123. 2013.

[19] Kleiber, P. B, Focus groups: More than a method of qualitative inquiry, in A \& A (Eds.), Foundations for research: Methods of inquiry in education and the social sciences, Mahwah, N.J, Erlbaum, 2004, 87-102.

[20] Anandarajan, M., Hill, C. and Nolan, T, "The fundamentals of content analysis," in Practical Text Analytics, 15-25. 2019.

[21] Boyatzis, R. E, Transforming qualitative information: Thematic analysis and code Development, Sage; London, UK, 1998.

[22] Starks, O, "Employer attitudes and beliefs about hiring postincarcerated offenders in Mississippi," Retrieved from Walden University Scholar Works. 2018.

[23] Schafer, E, "Mobilizing Meadville: The effects of food insecurity and community initiatives in low income communities," Retrieved August 31 from https://dspace.allegheny.edu/handle/10456/42942. 2017.

(C) The Author(s) 2019. This article is an open access article distributed under the terms and conditions of the Creative Commons Attribution (CC BY) license (http://creativecommons.org/licenses/by/4.0/). 